\title{
The Project to Complete the Regional Topographic Geodatabase in Lombardy, Italy
}

\author{
Piera Belotti ${ }^{a}$, Fabio Conzi ${ }^{\text {a }}$, Chiara Dell'Orto ${ }^{b}$, Maurizio Federici ${ }^{a}$, Luigi Fregonese ${ }^{\mathrm{c}}$, \\ Gabriele Garnero ${ }^{\mathrm{d}}$, Emilio Guastamacchia ${ }^{\mathrm{e}}$, Franco Guzzetti ${ }^{\mathrm{c}}$, Livio Pinto ${ }^{\mathrm{f}}$, Marco Scaioni ${ }^{\mathrm{c}}{ }^{\text {* }}$ \\ ${ }^{a}$ Direzione Generale Territorio e Protezione Civile, Regione Lombardia, Milano - [Piera_Belotti, Fabio_Conzi, \\ Maurizio_Federici]@regione.lombardia.it, bf free lancer-chiara.dellorto@gmail.com, \\ ${ }^{c}$ Dipartimento di Architettura, dell'Ambiente Costruito e dell'Ingegneria delle Costruzioni (DABC), Politecnico di Milano - \\ [luigi.fregonese, franco.guzzetti, marco.scaioni]@polimi.it, ${ }^{d}$ Dipartimento Interateneo di Scienze, Progetto e Politiche del \\ Territorio, Università degli Studi di Torino - gabriele.garnero@unito.it, ${ }^{e}$ Dipartimento di Architettura e di Studi Urbani (DAStU), \\ Politecnico di Milano emilio.guastamacchia@polimi.it, ${ }^{f}$ Dipartimento di Ingegneria Civile e Ambientale (DICA), Politecnico di \\ Milano-livio.pinto@polimi.it
}

* Corresponding author

\begin{abstract}
The Regional Topographic Geodatabase (DBTR) was officially defined in 2005 as the multi-scale (1:1,000 $1: 2,000-1: 5,000-1: 10,000)$ cartographic reference for urban and regional planning in Lombardy Region. The DBTR had been previously introduced at national level to take over traditional numerical topographic maps adopted for urban planning, with the aim to provide a base map to be implemented either at regional level (Regional Geoportal) and by local administrations. The DBTR is structured by following some national guidelines that define either the content and the topological structure, that makes simple its implementation in GIS environment. The construction of the entire DBTR has historically gone through different phases, with the consistent support of the regional subsidiary policy. But when the effects of the world economic crisis in 2008 became tangible in the budget of public administrations, the growth of the project faced an important break. In 2017 the administration of Lombardy Region has promoted and financed a new project finalized to the completion of the DBTR. A temporary association of mapping companies won the tender and completed the project by summer 2020, despite of the difficulties related to the COVID-19 pandemic. A team led by Politecnico di Milano was appointed for the quality assessment. The proposed paper would like to present this project and the operational solutions applied for the production of the new subsections of the DBTR, as well as its quality assessment/validation.
\end{abstract}

Keywords: Digital Mapping, Geodatabase, Regional Cartography, Topographic Database

\section{Introduction}

The Regional Topographic Geodatabase (DBTR) was officially defined in 2005 by the Regional Law $\mathrm{Nr}$. $12 / 2005$ for land government of the Lombardy Region as the multi-scale cartographic reference for urban and regional planning (see Regione Lombardia, 2020). This mapping product had been previously proposed and introduced by a working group including participants from the national government, the regional and local administrations from the whole country ('Intesa StatoRegioni-Enti locali sui sistemi informativi geografici IntesaGIS'). The aim of IntesaGIS was to define some standards for the development of multi-scale geodatabase able to fulfil either the needs of local management and land planning, and the needs of regional planning. Indeed, up until that time, Italian municipalities provided themselves with traditional numerical topographic maps in vector format (see Dell'Orto et al., 2004). These maps were commissioned by individual municipal administrations and obtained as output of the aerialphotogrammetry process at nominal scale 1:500, 1:1,000, $1: 2,000$ and 1:5,000, depending on the area to be mapped (historical downtown, unevenly urbanized areas, countryside, or mountain areas). Map updating was rarely operated, while in the long term those numerical maps were replaced after new aerial surveys. The main technical characteristic of these numerical maps was the accurate geometric content and graphical representation, but the inadequacy to be implemented in GIS environment. In fact, the need of base maps suitable for easy application in GIS has been continuously increasing in the last two decades.

Concurrently, the regional administrations of the twenty Italian Regions developed their own technical regional maps (CTR: "Carta Tecnica Regionale") in raster format at scale 1:5,000 and/or 1:10,000. The selection of the scale depended by the adopted regional policy. The CTR was adopted for land management and regional planning purpose. Specific aerial photogrammetric surveys were organized for the creation of the CTR, independently from projects to derive numerical maps at municipality level. Updating projects were also quite rare and, when present, less frequent than on a few-decades basis.

For the sake of completeness, it should be mentioned that in Italy the cadastral maps are separately managed by a national agency (Agenzia Entrate), see Agenzia Entrate 
(2019). Consequently, neither the local numerical maps nor the CTR integrate cadastral functions. The DBTR, unfortunately, inherited such a separation from the cadastral content, though some attempts to integrate this function have been and made (see, e.g., Tonelli et al., 2016). Due to the complexity of this problem, we omit to go deeper here.

In Lombardy region, the DBTR was conceived with the purpose of setting up a unique multi-scale digital map that could be directly implemented and handled in GIS environment. After a start-up phase when a few projects were autonomously developed by some municipality administrations (see, e.g, Scaioni et al., 2009), the regional administration brought up and funded a subsidiary policy to support the development of the DBTR has the unique regional geodatabase. Local partnerships including multiple municipalities could be freely established under the guidance of a public (e.g., a municipality, a province administration, a mountain community) or private (e.g., a facility management company) leader. Each consortia invested some money from its budget, which was integrated by funding from the regional administration. The aim was to yield a subsection of the DBTR covering the consortium's area of interest. The adopted scale was not the same everywhere but depended on the type of land use and terrain topography, the density of urbanization, and the available budget. In densely inhabited areas, nominal scales $1: 1,000$ or $1: 2,000$ were used, while nominal scales 1:5,000 and 1:10,000 were preferred for rural, forested and mountain areas (see Fig. 1).

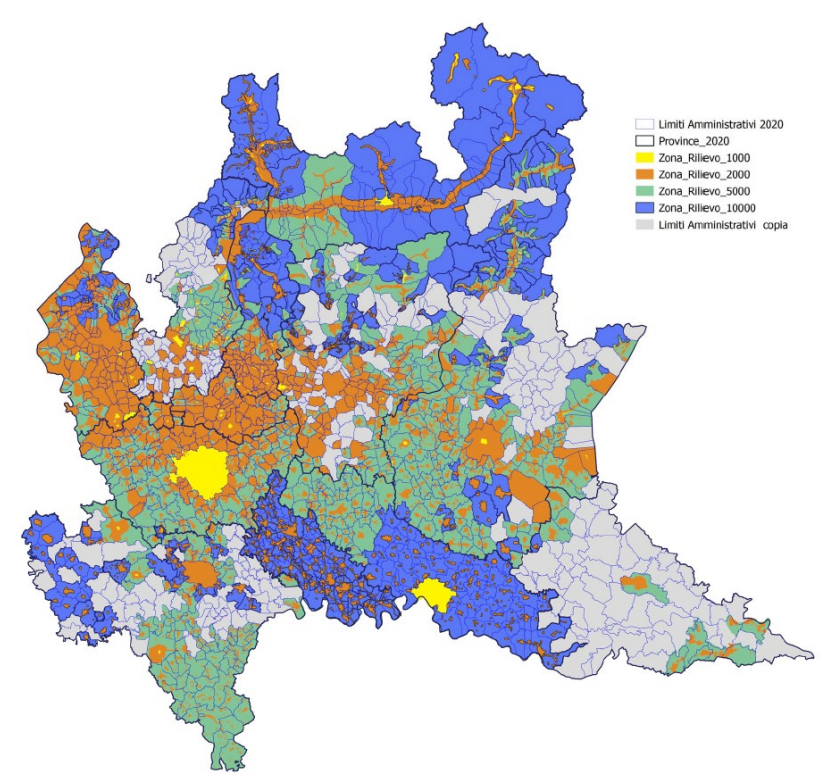

Figure 1. Status of the Regional Topographic Geodatabase (DBTR) of Lombardy region in 2017, when the completion project was started (grey areas). Areas where the DBTR was already available are colored depending on the nominal scale: 1:1,000 (yellow); 1:2,000 (brown), 1:5,000 (green), and $1: 10,000$ (blue).
The regional administration has issued a series of regulations for the DBTR production that were inspired by the national documents (Regione Lombardia, 2017). On the other, some tools for the final verification of the DBTR informatic structure were implemented and adopted to check-out that all new subsections of the DBTR were compatible with the regional regulations and formats. After this validation phase, these subsections could be transferred to the regional administration to be integrated and published in the Regional Geoportal (www.geoportale.regione.lombardia.it/home). In this way, the whole DBTR could be progressively built up. In addition, local projects were supposed to produce the update of the CTR raster map at scale 1:10,000, to gradually take over the old one.

In principle, new subsections of the DBTR should be obtained from new aerial surveys and based on the stateof-the-art aerial photogrammetry technology (INS/GNSS assisted flights, automatic aerial triangulation, digital stereo-plotting, integration of LiDAR data...). In some cases, already available numerical maps were used to derive the DBTR instead of using a photogrammetric process based on new aerial photos. This 'backup' solution, however, was rarely adopted to integrate as many municipalities as possible in the DBTR. The mainstream approach in Lombardia Region always consisted in the generation of the DBTR from surveyed data. Such a policy differed from some other Italian regions, which derived their DBTR from existing numerical maps.

These projects were developed up until 2015, mainly with the help of the regional economic subsidiary policy. This process led to an impressive growth of the whole DBTR in Lombardy, as shown in Figure 1. Unfortunately, when the economic effects of the world economic crisis in 2008 (Sanders, 2008) started to follow-up on the Italian public administration, a sudden inversion of the trend was observed.

Starting in 2017, the department ${ }^{1}$ of the Lombardy Region administration in charge of governing the development of the DBTR promoted a new project finalized to its completion. A total number of 262 municipalities spanning over five provinces of Lombardy were involved. This time, the regional administration directly managed the project without the economical cofunding by local partners.

A public tender was issued in three parts, one of which consisted in the independent quality assessment. A temporary association of Italian mapping companies won the tender and completed the project by summer 2020, despite of the severe difficulties and obstacles related to the development of COVID-19 pandemic in the country (Subsect. 2.1). A team lead by Politecnico di Milano

\footnotetext{
1 Struttura Sistema Informativo Territoriale Integrato della Direzione Generale Territorio e Protezione Civile (Structure for Integrated GIS of the General Direction on Land and Civil Protection).
} 
university was appointed for the quality assessment (Subsect. 2.2).

This paper would like to present the adopted approach and structure for the project to complete the DBTR (Sect. 2 ), and the operational solutions applied for producing its new subsections (Sect. 3), as well as the quality assessment/validation (Sect. 4). The modalities selected for publicly delivering data are described in Section 5 .

After almost fifteen years from the initial projects aimed at establishing this new type of geodatabase, the paper would like also to discuss somehow the role of the DBTR has developed and may be integrated in the spatial data infrastructure for the regional management in the new digital era (Sect. 6).

\section{The project}

On July 2017 the public tender for the selection of the companies for completing the DBTR was published. The project involved 262 municipalities in Lombardy region, spanning over five provinces (Bergamo, Brescia, Como, Mantova and Pavia). The public tender was organized in three subprojects, which are presented in the following subsections.

\subsection{Subprojects 1 and 2}

Subprojects 1 (89 municipalities) and $2 \quad$ (173 municipalities) concerned the completion of the DBTR in the uncompleted areas. Despite of the fact that both could be assigned to the same company (or aggregation of more companies - $\mathrm{RTI}^{2}$ ), the subdivision of the entire project into two separate subprojects was motivated by a twofold reason. On one side, the opportunity to get involved more companies in project funded by public money. On the other, the reduction of the project size. The practical subdivision (see Fig. 2) was based on merely geographic criteria: western and eastern parts whilst keeping all municipalities of the same province in the same subproject. As it can be seen in Figure 2, each subproject was split in two or three sections for organizational reasons.

Though Subprojects 1 and 2 were assigned through two independent tenders, the same temporary association (RTI) of Italian mapping companies won both because of the best combination of economic and technical offers. The winner RTI was composed by the following companies: Servizi di Informazione Territoriale S.r.l. (RTI leader), Aerosigma S.r.l., ARCADIA S.I.T. S.r.l., and Corvallis S.p.a.

\subsection{Subproject 3}

Subproject 3 concerned the quality assessment and validation of the production process and the final new sections of DBTR.

This subproject was assigned to an interdepartmental team of experts from Politecnico di Milano university. Three departments were involved: Architecture, Built environment and Construction engineering (DABC),

2 RTI: raggruppamento temporaneo di imprese (temporary grouping of companies).
Architecture and Urban Studies (DAStU), and Civil and Environmental Engineering (DICA). This team was integrated by external experts.

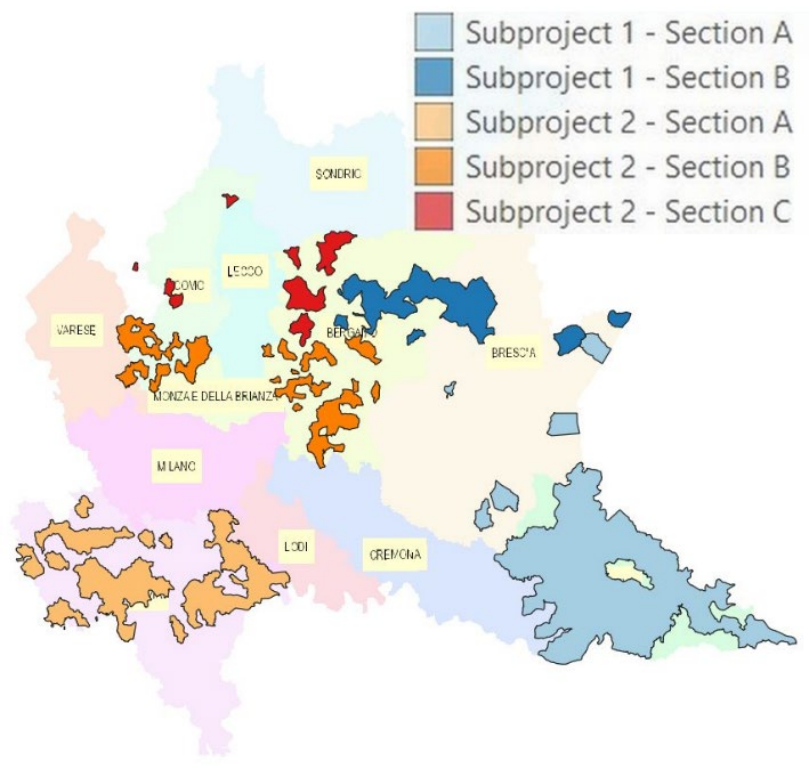

Figure 2. Organization of Subprojects 1 and 2 and their subsections. On the background, provinces are shown in light colors.

\subsection{Project organization}

\subsubsection{Photogrammetric data sets}

The new part of the DBTR that was completed during this project was derived from stereoplotting based on aerial photos. The photogrammetric data set was mostly derived by an already collected aerial imagery, complemented by a new specific aerial mission in 2019 .

The existing digital aerial images were collected in 2015 by AGEA (www.agea.gov.it), a national agency for supporting policies and funding in agriculture. This agency periodically (in general on a three-years basis) repeats the acquisition of photos over the entire country to feed the production of orthoimages to be used for successive analyses on the agricultural exploitation of lands. Under a policy of re-using public data sets for multiple purposes, the data 'AGEA 2015' were adopted to support the DBTR completion. This data set was also integrated by exterior orientation data computed through aerial triangulation. This task was certified by the Italian Geographic Military Institute (IGMI).

\subsubsection{Nominal scales, integration with existing DBTR}

The nominal scales selected to produce the new parts of the DBTR were:

- 1:2,000 for urbanized areas; and

- 1:5,000 for other areas (scarcely urbanized areas, countryside, mountain areas).

A couple of examples of the distribution of areas to be represented at different scales is shown in Figure 3.

The integration of the new sections with the existing DBTR was not in charge of the RTI. This task would be accomplished after the validation of the DBTR 
production by ARIA S.p.a. ${ }^{3}$, a company supporting the regional administration with technical and commercial issues. ARIA S.p.a. is also the manager of the Regional Geoportal where the DBTR is published and distributed.

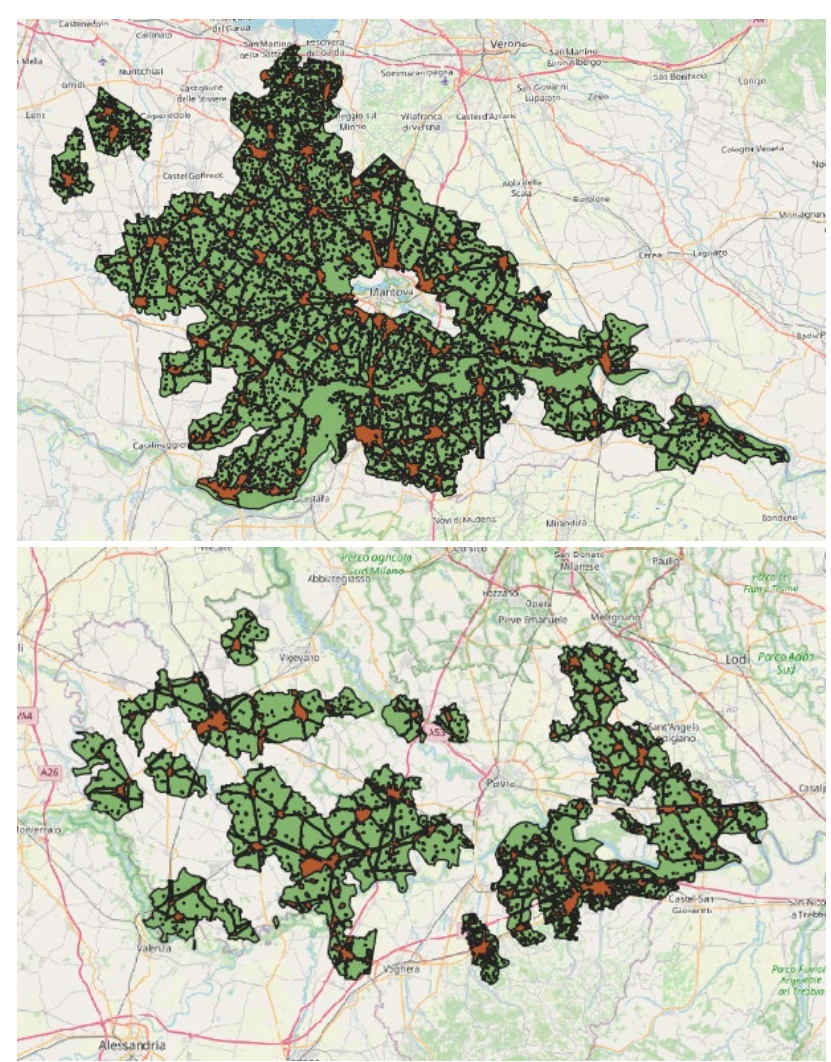

Figure 3. Examples of subdivision of areas to be represented at nominal scales 1:2,000 (brown areas) and 1:5,000 (green areas) in the new DBTR. In the upper part: Subproject 1/Section A (province of Mantova); in the lower part: Subproject 2/ Section A (province of Pavia). The base map is from OpenStreetMap (OSM).

\subsubsection{Technical specifications for the DBTR}

The content specification and the informatic structure of the new DBTR sections were ruled out by specifically tailored technical specifications. These evolved from the ones adopted to govern previous projects (see Regione Lombardia, 2017). Such a change was necessary to align the new project to those new national technical recommendations issued by the 'Working Group 2 Topographic GeoDB' of the Agency for Digital Italy, under the supervision of CISIS $^{4}$ and the support of the Permanent Committee for Geographic Systems (Agenzia per 1'Italia Digitale, 2015). At their turn, these technical specifications were simplified by eliminating some items that were retained redundant, with the aim of optimizing the DBTR production.

\footnotetext{
${ }^{3}$ Azienda regionale per l'Innovazione e gli Acquisti (Regional Agency for Innovation and Purchasing).

${ }^{4}$ Centro Interregionale per i Sistemi Informativi Geografici e Statistici (Interregional Centre for GIS and Statistical Information).
}

\subsubsection{Operational phases of the project}

The new project was organized in the following main operational phases, to be concurrently developed between Subprojects 1 and 2:

- Aerial survey, ground control point measurement, and aerial triangulation (only in those areas not covered by 'AGEA 2015' flight, see par. 2.3.1);

- Stereoplotting;

- Field reconnaissance; and

- DBTR structuring.

Each phase (or subphase in the case of multiple sections) was followed by the independent quality assessment (Subproject 3, see Sect. 4 in the following).

\section{The implementation}

The implementation of the project by the RTI was complex for technical and external reasons. Among the latter, the size of the DBTR to produce in short time represented a big challenge. Among the former, the meteorological conditions limited some operations (aerial survey and field reconnaissance), while the COVID-19 pandemic resulted in a temporary break of the project.

Here we will limit to analyse some technical aspects featuring more scientific relevance.

\subsection{Aerial survey}

Some important technical features of both aerial surveys adopted to produce the new DBTR are shown in Table 1. Those areas not covered by 'AGEA 2015' flight were interested by a new aerial-survey mission in 2019. The external orientation of new images was computed by the automatic aerial triangulation, where a few ground control points were included to integrate the IMU/GNSS observations recorded during the flight. An example of a digital image from the 'AGEA 2015' flight is shown in Figure 4. The regional coverage of orthoimages obtained from this flight can be found on the Regional Geoportal (Regione Lombardia, 2021a), or linked to a Web Map Service (OGC, 2021).

\begin{tabular}{|l|l|l|l|l|l|}
\hline $\begin{array}{l}\text { Aerial } \\
\text { survey } \\
\text { project }\end{array}$ & $\begin{array}{l}\text { Adopted } \\
\text { digital } \\
\text { cameras }\end{array}$ & $\begin{array}{l}\text { Focal } \\
\text { length }\end{array}$ & $\begin{array}{l}\text { Image } \\
\text { size }\end{array}$ & $\begin{array}{l}\text { Pixel } \\
\text { size }\end{array}$ & $\begin{array}{l}\text { Mean } \\
\text { GSD }\end{array}$ \\
\hline $\begin{array}{l}\text { 'AGEA } \\
2015 \text { ' }\end{array}$ & $\begin{array}{l}\text { Vexcel } \\
\text { UltraCam } \\
\text { Xp (\#2 } \\
\text { cameras) } \\
\text { Vexcel } \\
\text { Mark 3 }\end{array}$ & 100.50 & $\begin{array}{l}\text { pixels } \\
11310 x\end{array}$ & $\begin{array}{l}\mu \mathrm{m} \\
17310\end{array}$ & $\mathrm{~cm}$ \\
2019 & 122.70 & $\begin{array}{l}17004 \mathrm{x} \\
26460\end{array}$ & 4 & 18 \\
flight
\end{tabular}

Table 1. Characteristics of the aerial surveys adopted for the project to complete the DBTR in Lombardy region (GSD means: ground sampling distance).

\subsection{Stereoplotting and DTM}

Stereoplotting from aerial images was used to derive an intermediate vector map made up of those $3 \mathrm{D}$ features to 
be used for the setup of the DBTR. The reconstruction of those elements to represent the terrain topography (i.e., contour lines and height points) was based on the preliminary production of a digital terrain model (DTM). Such a model was obtained by integrating existing DTMs from LiDAR data, after assessment (see Regione Lombardia, 2021b). Where DTM was not available, a new digital surface model (DSM) was obtained based on photogrammetric processing ('dense matching' - see Remondino et al., 2014) followed by filtering to remove off-terrain points.

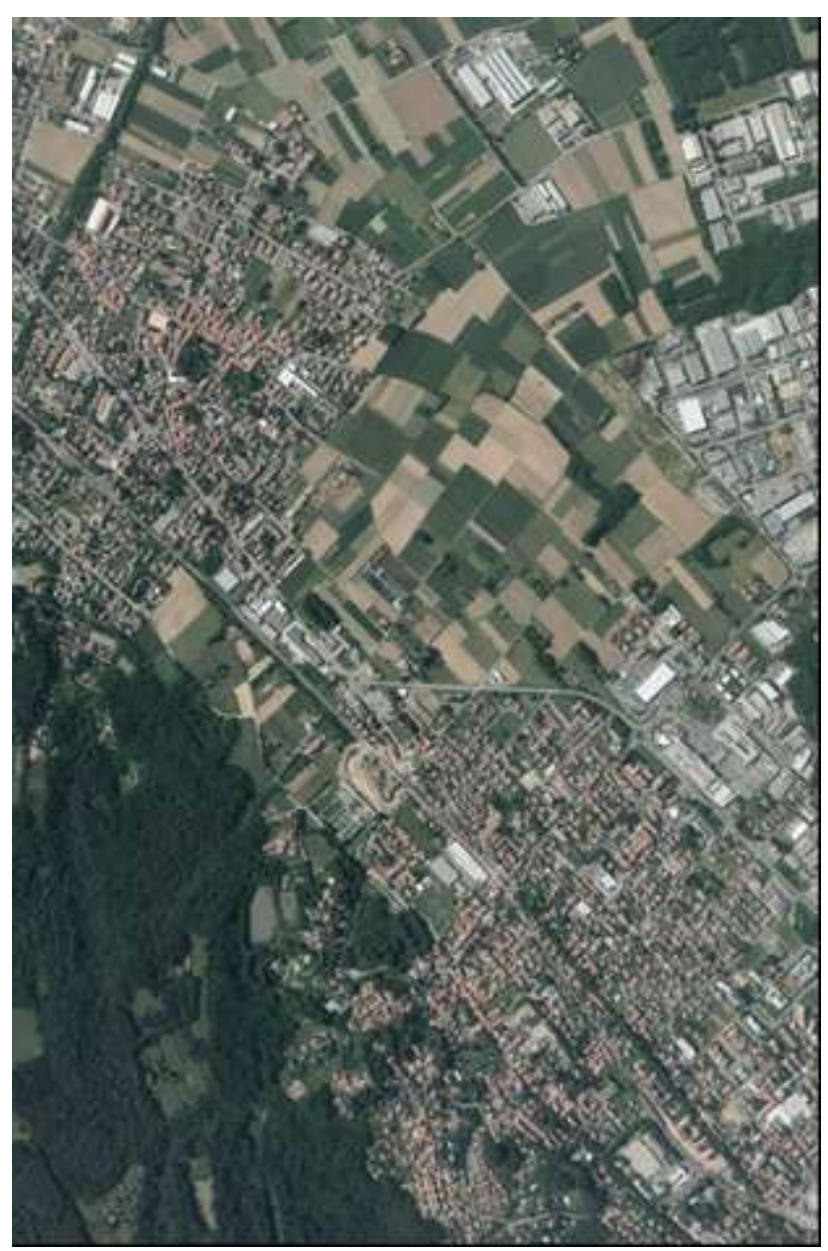

Figure 4. Example of an aerial image from 'AGEA 2015' flight (copyright by AGEA).

\subsection{Field reconnaissance}

The three-dimensional content reconstructed from stereoplotting was integrated and validated during an extensive field reconnaissance. A team of expert operators was sent by the RTI to explore all areas of numerical vector maps obtained from stereoplotting (not yet transformed into DBTR), with major work on the areas to be represented at nominal scale 1:2,000. In some sections, the field reconnaissance was supported using an experimental software application installed on a tablet, that allowed to record georeferenced annotations and geometric corrections on the intermediate vector map. The adopted application was developed on purpose by the
RTI. After the completion of each field reconnaissance mission, the annotated information could be directly imported in the editing environment where the intermediate vector map was used to create the DBTR structure (to be archived in ESRI Shapefile format).

The field reconnaissance resulted as the most critical phase of the entire project. This was mainly due to the extension of the areas to map and, very often, the urbanistic complexity of the urban areas. For this reason, the introduction of software applications to support this task could give a great support. This practice should become a standard in future mapping projects when a high level of detail is required.

\section{Quality control}

A crucial step of this project was constituted by the independent technical verification and assessment. This task was the specific aim of Subproject 3 assigned to a team from Politecnico di Milano university, integrated by some external experts.

The quality control process was based on two main series of technical verifications. The first group consisted in specific technical checks during each production phases per each subproject/section (see par. 2.3.4). Analyses were operated after the delivery of the intermediate final products of each intermediate step, as prescribed by the technical regulations of the project. The quality control team was in charge to assess the adopted methods, materials, and the intermediate and final products. Results of the analyses on a single phase were reported in technical reports, organized by following a common structure as proposed in Scaioni (2005).

The last analysis from the first group of technical verifications consisted in the metrical assessment. This operation is traditionally carried out at the end of mapping projects developed in the country. It is based on the selection of a consistent sample of 3D check points (and/or relative interdistances and elevation differences) from the DBTR, to be independently remeasured on the field by using modern geomatic techniques. The analysis of the discrepancies between the coordinates of check points from the DBTR and the new independent measurements were analysed based on:

- $\quad$ The mean values of the discrepancies, to assess the presence of possible bias;

- The standard deviations of the discrepancies, to analyse the dispersion of errors; and

- The fraction of check points outside of the mapping tolerances.

This analysis was repeated in a set of sample municipalities of the whole projects, to be representative of the different 'homogenous production areas' (see an example in Fig. 5). Each 'homogenous production area' has been operated by the same company in the RTI, belongs to the same Subproject/Section and is characterized by similar type of terrain topography. concerned the different coordinates. Inside these areas, some zones were selected to measure check points, as 
shown by red circles in Figure 5. Points were selected in correspondence of non-ambiguous and distinct features by using GNSS-RTK technique linked to the public positioning service SPIN 3 GNSS available in Lombardy (www.spingnss.it).

The second types of the analyses concerned the final DBTR. By using a software application developed by the administration of Lombardy region, the quality control team could apply this tool for the conformity analysis of the final production. On the other hand, the same tool was also made available to the RTI for internal verification.

The conformity of the final DBTR was a fundamental prerequisite for integrating the new production in the entire DBTR, to be published and delivered through the Regional Geoportal (see next Sect. 5).

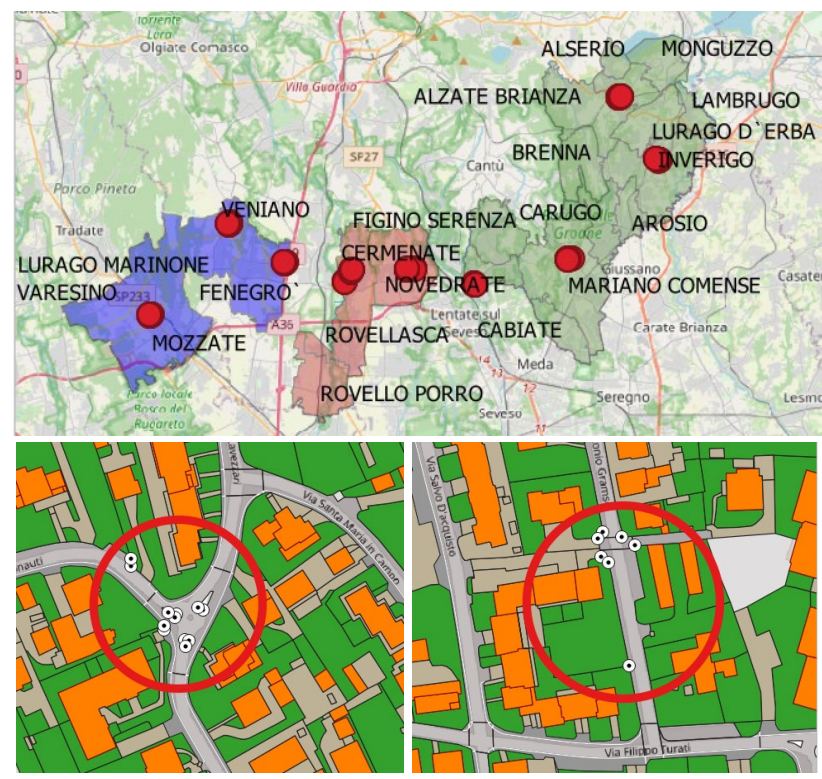

Figure 5. Location of control points for the final quality control of the DBTR in three 'homogenous production areas' (in blue, brown and green areas) belonging to Subproject 2/Section B of the project. Red circles in the upper figure show where investigated areas were selected. Two of them in the municipality of Cermenate are zoomed in the lower subfigures, where check points are displayed (black-white dots). The base map is from OSM in the upper figure, while in the lower the DBTR is used.

\section{Public delivery of the DBTR}

After the completion of Subprojects 1, 2 and 3, the DBTR was delivered to the managers of the Regional Geoportal (www.geoportale.regione.lombardia.it/home), which is operated by ARIA S.p.a.

Before the publication, the new sections of the DBTR were integrated with the already existing ones. After this task, data are publicly delivered through the Regional Geoportal in two modalities (see Regione Lombardia, 2021c):

1. Data may be visualized, overlaid to other geographic layers, and queried in the Geographic Viewer (Fig. 6); and
2. Data may be downloaded by users, either after direct selection in the Geographic Viewer, and by downloading of the entire DBTR corresponding to a specific municipality, to a province or a to metropolitan area (Milano).

The Geographic Viewer allows to display the DBRT at prefixed scale steps ranging from 1:3,000,000 for chorographic purpose, to $1: 1,000$ for detailed visualization. At the most detailed scale $(1: 1,000)$, informative attributes of single objects can be displayed. In Figure 7 the same geographic area is displayed at different scales. At the moment of writing, no WMS is available on the Regional Geoportal to access the DBTR data. The raster CTR (see Sect. 1) derived from the updated DBTR is available (Regione Lombardia, 2021d). In addition, all municipalities involved in the project were directly provided by the portion of DBTR corresponding to their administrative territory. All municipalities of the entire region were also invited to some events for promoting the use of the DBTR and to train their own staff members.

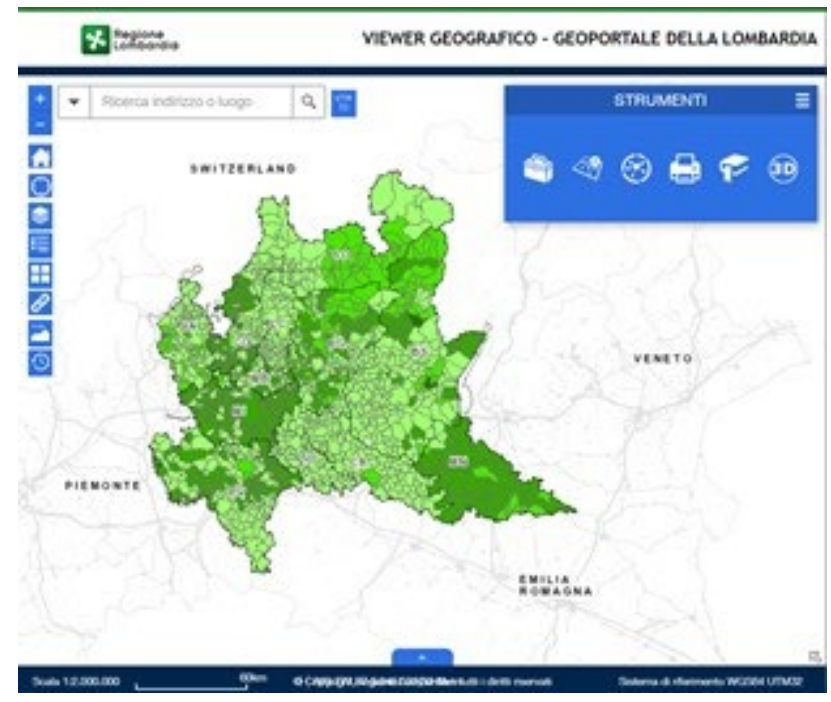

Figure 6. The Geographic Viewer of the Regional Geoportal for the visualization of the DBTR and other geographic information related to the region. In this figure, the scale of displayed data is $1: 2,000,000$, but it may range at prefixed steps from $1: 3,000,000$ to $1: 1,000$.

\section{Conclusions and future developments}

In 2017 the administration of Lombardy region started a project for the completion of the Regional Topographic Geodatabase (DBTR), which is the multi-scale cartographic reference for urban and regional planning. In summer 2020, a group of mapping companies appointed to accomplish the project, completed the implementation of the new sections of the DBTR. Starting from the beginning of the development of the DBTR in the early 2000's, now an important step forward has been done with the completion of this project. 


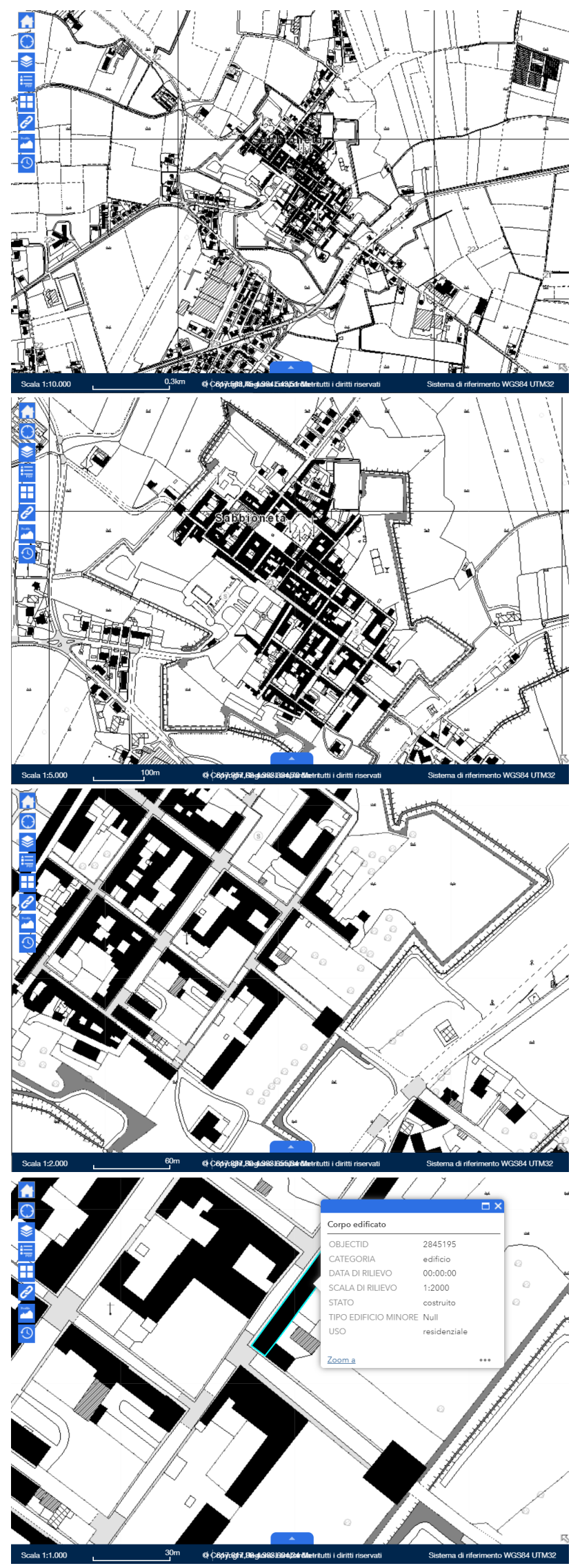

Figure 7. A portion of the DBTR in the historical town of Sabbioneta (province of Mantua) is displayed at four different scales in the Geographic Viewer. Objects' properties can be displayed at visualization scale 1:1,000.
This achievement opens several perspectives and challenges, keeping also into consideration the current great impulse towards the digitalization of public administration processes. Among all, we would like to focus on two main aspects.

The first important issue to face now is the update of the DBTR. Geographic information derived from this project dates to 2015 and 2019, times of the aerial surveys (Subsect. 3.1). But the most remaining parts, with few exceptions, were obtained from older projects and aerial surveys carried out in the decade before. For this reason, a new project for updating the entire DBTR based on more recent AGEA aerial survey (Par. 2.3.1) is under preparation. But strictly related to this point is the necessity of establishing a workflow for exchanging data from and to the local administrations. Indeed, when a municipality (or another local body) repeats a new data acquisition and updates the local section of the DBTR, it's easy to replace it in the Regional Geoportal. On the other hand, local administrations, which have established their own GIS and link the DBTR to other types of data or services, would require other strategies for keeping their data aligned with respect to the Regional Geoportal (see, e.g., Regione Emilia Romagna, 2012). About the update of the DBTR, the investigation on the use of Earth Information coming from the satellite constellations (e.g., from EU Copernicus programme) is also an important challenge.

The second aspect is related to the fact that the DBTR is a standard geodatabase at regional ${ }^{5}$ level. This opens the way to adopt the DBTR data as hub for connecting several types of geocoded information which may characterize some important classes of objects. For example, the integration of cadastral data (land and buildings - see Guzzetti and Pasquinelli, 2012), the access to public utility and energy consumption data (Pasquinelli et al., 2019), the data exchange with BIM (Building Information Modelling - see Garramone et al., 2020), among others.

Last comments are related to organization and development of this project. The impressive amount of data to process and the extension and density of the territory to be surveyed and represented in the DBTR have revealed that the technical preparation stage of such projects is impressively important for both the public administration and the companies involved. About the quality control, a dramatic change will be necessary in the future to extend the assessment to the full production process, and not only to the intermediate and final products. The introduction of the new digital tools to record and track any operational tasks (e.g., to support the field reconnaissance) are expected to improve the quality of the different production phases of the DBTR.

\footnotetext{
5 Theoretically the DBTR should also be a national standard, due to the compliance to national guidelines. But this would depend on the policies adopted by other regions.
} 


\section{Acknowledgements}

This project was possible thanks to the support from POR FSE 2014-2020 axis iv/investment priority 11.ii/action 11.1.2. Acknowledgements also go to ARIA S.p.a., the companies of the RTI, and to those colleagues from the administration of Lombardy region, Politecnico di Milano (Prof. Andrea Adami and Dr. Alessandro Mandelli) and the RTI who helped with the operations.

\section{References}

Agenzia Entrate, 2019. Il Sistema Catastale - Edizione 2019. https://www.agenziaentrate.gov.it/portale/ documents/20143/233848/Il+sistema+catastale+2019_Il + Sistema + Catastale $+2019+\% 28 d a t i+2018 \% 29 . p d f / a a 6 a$ 5b0b-600a-0299-33e5-bf7bc495991b (last access on 22/08/2021), in Italian.

Agenzia per l'Italia Digitale, 2015. Catalogo dei dati territoriali. Specifiche di contenuto per i DataBase Geotopografici. Ver. 2.0 (15/12/2015). https:// geodati.gov.it/geoportale/images/Specifica_GdL2_0905-2016.pdf (last access on 17/08/2021), in Italian.

Dell'Orto, C., Guzzetti, F., Molteni, S., Ratti, M., 2004. Esperienze di adeguamento di una cartografia numerica a database topografico. Documenti del Territorio, vol. 55, pp. 24-31, in Italian.

Garramone, M., Moretti, N., Scaioni, M., Ellul, C., Re Cecconi, F., Dejaco, M.C., 2000. BIM and GIS Integration for Infrastructure Asset Management: A Bibliometric Analysis. ISPRS Ann. Photogramm. Remote Sens. Spatial Inf. Sci., vol. VI-4, part W1-2020, pp. $77-84$

Guzzetti, F., Pasquinelli, A., 2012. L'integrazione tra DbT e Catasto: un nuovo strato informativo per la gestione del territorio tramite GIS. GEOmedia, vol. 4, pp. 6-10, in Italian.

OGC (Open Geospatial Consortium), 2021. Web Map Service. https://www.ogc.org/standards/wms\#overview (last access on 23/08/2021).

Pasquinelli, A., Agugiaro, G., Tagliabue, L.C., Scaioni, M., Guzzetti, F., 2019. Exploiting the Potential of Integrated Public Building Data: Energy Performance Assessment of the Building Stock in a Case Study in Northern Italy. ISPRS Int. J. Geo-Inform., vol. 8, paper No. 27, 31 pages.

Regione Emilia Romagna, 2012. Linee Guida per l'aggiornamento cooperativo del DBTR. https://geoportale.regione.emilia-romagna.it/

approfondimenti/contenuti-

allegati/linee_guida_aggiornamentodbtr_giugno2012.pd f/@@download/file/Linee_guida_aggiornamentoDBTR giugno2012.pdf (last access on 23/08/2021), in Italian.

Regione Lombardia, 2017. Specifiche Tecniche Database Topografico. https://www.geoportale.regione. lombardia.it/specifiche-tecniche (last access on $17 / 08 / 2021)$, in Italian.

Regione Lombardia, 2020. Database Topografico Regionale (DBTR). https://www.regione.lombardia.it/ wps/portal/istituzionale/HP/DettaglioServizio/servizi-einformazioni/Enti-e-Operatori/Territorio/sistema- informativo-territoriale-sit/database-topograficoregionale/database-topografico-regionale (last access on $17 / 08 / 2021)$, in Italian.

Regione Lombardia, 2021a. Ortofoto AGEA 2015. https:/www.geoportale.regione.lombardia.it/metadati?p _p_id=detailSheetMetadata_WAR_gptmetadataportlet \&p_p_lifecycle $=0 \& p \_p \_s t a t e=$ normal $\& p \_p \_$mode $=v i e$ w\&_detailSheetMetadata_WAR_gptmetadataportlet_uu $\mathrm{id}=\%$ 7B6187332D-EF71-469D-9D87-

D8214BA7E85E\%7D (last access on 22/08/2021), in Italian.

Regione Lombardia, 2021b. DTM5x5 - Modello digitale del terreno (ed. 2015). https://www.geoportale.regione. lombardia.it/metadati?p_p_id=detailSheetMetadata_W AR_gptmetadataportlet $\& p \_p \_$lifecycle $=0 \& p \_p \_s t a t e=n$ ormal\&p_p_mode $=$ view\&_detailSheetMetadata_WAR_ gptmetadataportlet_uuid $=\%$ 7BFC06681A-2403-481FB6FE-5F952DD48BAF\%7D (last access on $22 / 08 / 2021)$, in Italian.

Regione Lombardia, 2021c. Metadati Database Topografico (DBT) regionale: data di rilievo/aggiornamento. https://www.geoportale.regione. lombardia.it/en-

GB/metadati?p_p_id=detailSheetMetadata_WAR_gptm etadataportlet\&p_p_lifecycle $=0 \& p \_p \_s t a t e=$ normal $\& p$ p_mode $=$ view\&_detailSheetMetadata_WAR_gptmetada taportlet_uuid=\%7B1CE0E71B-6451-4B5D-8E4D-

BC0FF6E0A46F\%7D (last access on 19/08/2021), in Italian.

Regione Lombardia, 2021d. Carta base da DBT. https://www.geoportale.regione.lombardia.it/enGB/metadati?p_p_id=detailSheetMetadata_WAR_gptm etadataportlet\&p_p_lifecycle $=0 \& p \_p \_s t a t e=$ normal $\& p$ p_mode=view\&_detailSheetMetadata_WAR_gptmetada taportlet_uuid $=\%$ 7B6FB7DE9A-EE54-45EC-B61C-

A4147CF752D0\%7D (last access on 23/08/2021), in Italian.

Remondino, F., Spera, M.G., Nocerino, E., Menna, F., Nex, F., 2014. State of the art in high density image matching. Photogramm. Rec., vol. 29, pp. 144-166.

Sanders, A., 2008. The subprime crisis and its role in the financial crisis. J. Housing Econ., vol. 17, pp. 254-261.

Scaioni, M., 2005. Proposta di una procedura standardizzata per il controllo di qualità dei DB topografici. In: Atti Conv. Naz. SIFET, 29/0601/07/2005, Palermo Mondello, Italy, pp. 10, in Italian.

Scaioni, M., Guastamacchia, E., Crimella, E., 2009. The Topographic $\mathrm{Db}$ as a tool for land management and government: The 'Provincia di Lecco project'. In: M. Caglioni, F. Scarlatti (eds.), Representation of Geographical Information for Planning, Ed. Esculapio, Bologna, Italy, pp. 29-38.

Tonelli, E., Guzzetti, F., Baragetti, E., Colombo, P.F., Caspani, P., Viskanic, P., Scaioni, M., 2016. Un percorso per l'integrazione dei Database Topografici con le informazioni del Catasto dei Terreni nelle zone 'a perimetro aperto'. In: Proc. 20 a Conf. Naz. ASITA, Cagliari, Italy, 8-10/11/2016, pp. 623-630, in Italian. 